Chase, M. W. (1963). La Tolerance Acquise et la Tolerance Naturelle a l'egard de Substances Antigenique Definies. Paris, Centre National de la Recherche Scientifique.

Chilgren, R. A., Meuwissen, H. J., Quie, P. G., Good, R. A., and Hong, R. (1969). Lancet, 1, 1286.

Da Silva Lacaz, C. (1967). Compendio de Micologia Medica. Sao Paulo, Sarvier.

Festenstein, H., Abrahams, C., and Bockkenheuser, V. (1967). Clinical and

Experimental Immunology, 2, 311.
Frei, W. (1928a). Klinische Wochenschrift, 7, 539.

Frei, W. (1928a). Klinische Wochenschrift, 7, 539.
Frei, W. (1928b). Klinische Wochenschrift, 7, 1026.

Frey, J. R., de Weck, A. L., and Geleick, H. (1964). Fournal of Investigative Dermatology, 42, 189.

Jadassohn, J. (1896). Verhandlungen der Deutsche Dermatologischen Gesellschaft, $5,103$.

Johansson, S. G. O., and Juhlin, L. (1970). British fournal of Dermatology, 82,10 .

Juhlin, L., Johansson, S. G. O., Bennich, H., Hogman, C., and Thyresson N. (1969). Archives of Dermatology, 100, 12.

Landsteiner, K., and Chase, M. W. (1942). Proceedings of the Society for Experimental Biology and Medicine, 49, 688 .

Levene, G. M., Turk, J. L., Wright, D. J. M., and Grimble, A. G. S. (1969). Lancet, 2, 246.

Low, R. C. (1924). British Fournal of Dermatology and Syphilis, 36, 292.
Miescher, P. A., Paronetto, F., and Koffler, D. (1966). In Immunopathology IVth International Symposium, ed. P. Grabar and P. A. Miescher, p. 446. Basel, Schwabe.

Newell, K. W. (1966). Bulletin of the World Health Organization, 34, 827. Pierpaoli, W., Baroni, C., Fabris, N., and Sorkin, E. (1969). Immunology, $16,217$.

Pirquet, C. von (1906). Münchener medizinische Wochenschrift, 53, 1457.

Polàk, L., Barnes, J. M., and Turk, J. L. (1968). Immunology, 14, 707.

Polàk, L., and Turk, J. L. (1968). Clinical and Experimental Immunology, 3,

Rees, R.ण. W., Waters, M. F. R., Weddell, A. G. M., and Palmer, E. (1967). Nature, 215, 599.

Ridley, D. S., and Jopling, W. H. (1966). International fournal of Leprosy, $34,255$.

Sulzberger, M. B. (1929). Archives of Dermatology and Syphilology, 20, 669.

Sulzberger, M. B. (1940). Dermatologic Allergy. Springfield, Illinois, Thomas.

Tan, E. M., and Stoughton, R. B. (1969), Proceedings of the National Academy of Sciences of the United States of America, 62, 708.

Turk, J. L., and Waters, M. F. R. (1968). Lancet, 2, 436.

Turk, J. L., and Waters, M. F. R. (1969), Lancet, 2, 243.

Varelzidis, A., Wilson, A. B., Meara, R. H., and Turk, J. L. (1966). British Medical fournal, 2, 925.

Wemambu, S. N. C., Turk, J. L., Waters, M. F. R., and Rees, R. J. W. (1969). Lancet, 2, 933.

\title{
Duodenal Ulcer and Recurrent Dyspepsia
}

\author{
G. K. H. HODGKIN, ${ }^{*}$ B.M., M.R.C.P., F.R.C.G.P. ; R. FREEDMAN, $†$ M.B., B.CHIR., M.R.c.G.P. \\ I. FULLER, $\ddagger$ M.B., M.R.c.G.P., D.oBST.R.c.o.G. ; J. WHEWELL, $\$ M.B., M.R.C.G.P., D.oBST.R.c.o.G.
}

\begin{abstract}
Summary: A survey of recurrent indigestion in four general practices $(19,619$ patients) showed a wide range of dyspeptic complaints. Of these $82(4 \cdot 2$ per $1,000)$ already had a proved ulcer and $144(7.3$ per 1,000$)$ had symptoms suggesting a duodenal ulcer and had either not been investigated or had previously had a normal barium meal. A duodenal ulcer was found radiologically in half the men (46 out of 95 ) but in only $16 \%$ of the women (8 out of 49$)$. In $11(25 \%)$ of the 46 men shown to have an ulcer a barium meal had been previously reported as normal. Evidence is put forward that ulcer symptoms in the large residue of patients with a normal barium meal ( 38 men, 29 women) were produced by a primary duodenal condition (duodenitis) of which ulcer was one complication.
\end{abstract}

\section{Introduction}

In general practice the spectrum of dyspeptic complaints is very wide. On the one hand are the clearly defined and welldocumented pathological conditions often seen in hospital; on the other are the many cases of minor recurrent indigestion rarely reported to the doctor. The great variations in symptom severity and radiological techniques have led to difficulties in estimating both prevalence and aetiology. Consequently there has been a confusing multiplicity of names-some clinical, others implying a disorder as yet unproved. Doll and Avery Jones (1951) called the condition of dyspepsia with apparently normal barium-meal appearances "presumptive peptic ulcer"; other terms proposed have been pseudoulcer (Barfred, 1958), duodenitis (Beck et al., 1965), and nonulcer dyspepsia (Edwards and Coghill, 1968).

We were especially, interested in those patients with a history suggesting duodenal ulcer in whom barium studies showed no abnormality. We correlated the evidence of radiology, ABO blood group, ABH secretor status, and serum pepsinogen with clinical findings in an attempt to provide basic information about those problems of incidence,

\footnotetext{
* General Practitioner, Redcar, Yorkshire.

General Practitioner, Sedgefield, Durham.

General Practitioner, Middlesbrough, Yorkshire.
}

aetiology, and management that make the handling of these patients difficult in general practice.

\section{Methods and Materials}

Four practices in north-east England (three urban, one rural) involving nine doctors and 19,619 National Health Service patients took part in the project. Diagnostic indexes were kept by each practice, thus every patient reporting with recurrent or chronic indigestion could be identified and later questioned. This technique allowed the first phase of case selection to be carried out on a routine basis without observer bias and ensured inclusion of the complete spectrum of recurrent dyspepsia encountered by the doctors.

Ulcer-type Dyspepsia.-This clinical label is used for those patients with apparently normal barium-meal appearances and the following symptom triad : periodicity involving two or more attacks of upper abdominal pain during the previous two years; combined duration of such attacks of six or more days; and relief of this pain by food, milk, or alkalis. Throughout this paper duodenal ulcer, gastric ulcer, and chronic cholecystitis refer to radiologically diagnosed cases unless otherwise stated. Reflux oesophagitis refers to all cases in which oesophageal reflux or hiatus hernia has been demonstrated by $x$-ray examination.

Nervous dyspepsia (including functional gastritis) refers to all cases of ill-defined recurrent dyspepsia in which the symptom triad was incomplete.

Between 1 January and 30 September 1966351 patients reported to the practices with recurrent dyspepsia of varying origin. These patients were later contacted and the following procedures instigated :

A standardized clinical history, examination, and radiological investigation were arranged. Blood and saliva were taken for three purposes: (a) ABO group; Aird et al. (1954) showed that the incidence of duodenal ulcer was high in group $O$ patients. (b) ABH secretor status; Clarke et al. (1956) showed that the incidence of duodenal ulcer was high in non-secretors-that is, patients who do not secrete blood group antigens in their saliva. (c) Serum pepsinogen; Spiro et al. (1956) and Mirsky et al. (1952) showed that serum pepsinogen was related to a high gastric acid secretion and was raised in duodenal ulceration. The method of estimation was that of Hanley (1964). 
At this stage the material was divided into four groups representing the dyspeptic spectrum encountered, as shown in Table I.

General practitioners are always afraid of overlooking carcinoma, but none of the three cases encountered during the survey period was confused with any of the groups in Table I.

TABLE I

\begin{tabular}{|c|c|c|c|}
\hline Groups (Total 351) & No. & Male & Female \\
\hline $\begin{array}{l}\text { (1) Patients with previously well-established disease; } \\
\text { a check barium meal was arranged } \\
\text { (2) Patients fulfilling the three clinical criteria for } \\
\text { ulcer-type dyspepsia; a barium meal was arranged } \\
\text { (some had previously had a normal barium meal) } \\
\text { (3) Patients with nervous dyspepsia; no further } \\
\text { investigations were arranged } \\
\text { (4) Patients whose conditions were too indefinite to } \\
\text { qualify for any of the above. These were discarded }\end{array}$ & $\begin{array}{r}117 \\
144 \\
51 \\
39\end{array}$ & $\begin{array}{l}95 \\
23 \\
13\end{array}$ & $\begin{array}{l}45 \\
49 \\
28 \\
26\end{array}$ \\
\hline
\end{tabular}

Groups 1-3 form the basis of this paper. A random sample of 186 controls stratified by age, sex, and practice was taken from the age/sex registers of the four practices. Stratification is more flexible than direct matching of controls, and was undertaken on statistical advice.

The above material has been analysed in two stages (Table II): (1) The results of radiological examination on 144

TABLE II

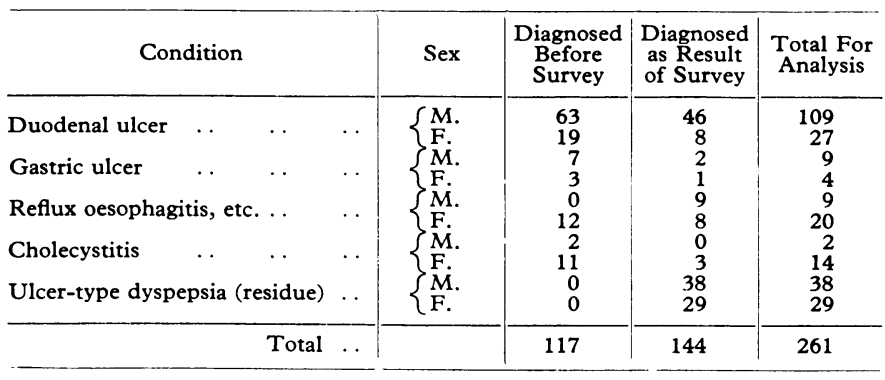

patients with the ulcer-type dyspepsia clinical triad. (2) The comparison both clinical and aetiological, of the different disease entities. For this purpose those conditions unearthed during our investigation were added to those with an already established diagnosis (Table II).

\section{Results}

Eighty-two patients $(4.2$ per 1,000$)-63$ men and 19 womenreported with a known duodenal ulcer. Nearly twice this number (144; 7.3 per 1,000)-95 men and 49 womenreported with a clinical history suggestive of duodenal ulcer (Table II). Fifty-one patients ( 2.6 per 1,000$)-23$ men and 28 women-reported with atypical nervous dyspepsia-that is, the ulcer-type dyspepsia clinical triad was incomplete (group 3, Table I). The numbers of patients encountered during the survey period with gastric ulcer, reflux oesophagitis, and cholecystitis are also given in Table II.

\section{Radiological Investigation}

Barium studies in the 144 patients with a history suggesting duodenal ulcer revealed that : (1) Of the 95 men $46(48 \%)$ had a duodenal ulcer, and 11 of these had previously had a normal barium meal; 11 (12\%) had other lesions; and $38(40 \%)$ remained as an undiagnosed residue of ulcer-type dyspepsia. (2) Of the 49 women only $8(16 \%)$ had a demonstrable duodenal ulcer. The number of undiagnosed patients with ulcer-type dyspepsia remaining was proportionately larger- 29 out of $49(59 \%)$. A large proportion, 12 out of $49(25 \%)$, had other lesions, for example hiatus hernia or cholecystitis.

\section{Comparison of the Different Diagnostic Groups}

This investigation isolated and clarified a confused part of the spectrum of recurrent dyspepsia as presented to the general practitioner. As diagnoses became more definite, valid comparisons between the different groups were possible. Similarities and differences between these groups could be used to achieve earlier and more accurate diagnosis as well as a better understanding of aetiology.

(1) Clinical Similarities.-The triad of symptoms considered by us to be most characteristic of duodenal ulcer was by definition present in all the ulcer-type dyspepsia residue of cases. There were, however, many further similarities between this group and the group with a proved duodenal ulcer. In both men and women the distribution curves for onset of duodenal ulcer and ulcer-type dyspepsia were similar (Fig. 1). In contrast, reflux oesophagitis in females-the only other group large enough for comparison-showed a different distribution, a larger proportion of cases developing after the age of 40 years. Analysis of nine other symptoms characteristic of duodenal ulcer showed that their frequency in the two groups was also similar. Statistically significant differences were seen in only two instances-periodicity and weight loss. B॰th symptoms were significantly more pronounced in patients with a proved duodenal ulcer, but both are indices of symp-

TABLE III.-Frequency (\%) of Selected Symptoms in Various Groups of Conditions Examined

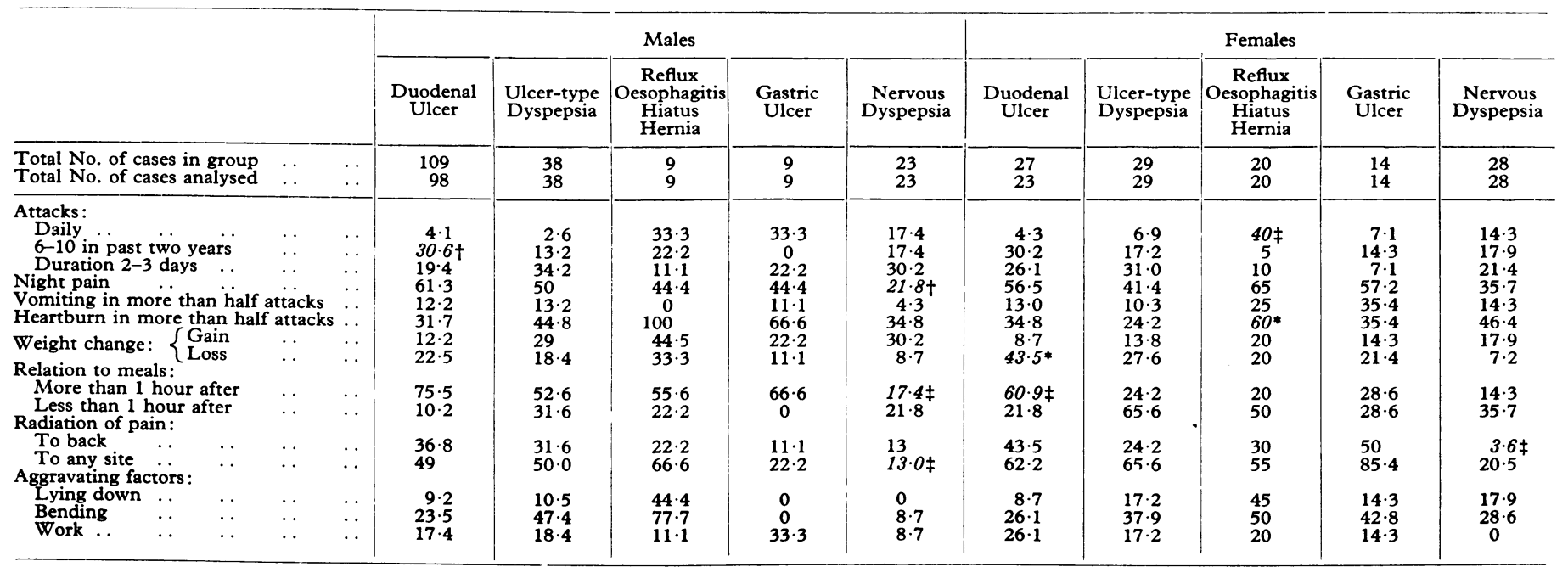




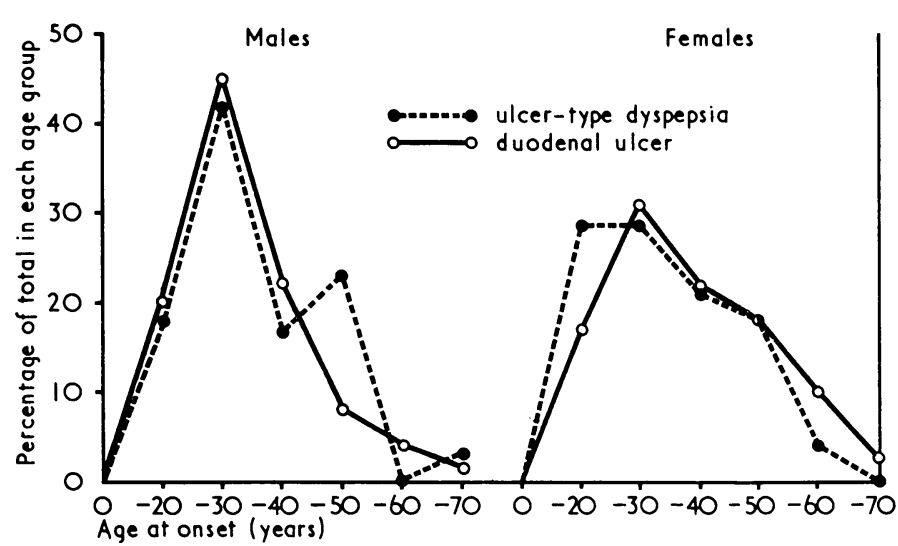

Fig. 1.-Distribution curves for onset of duodenal ulcer and ulcer-type dyspepsia.

tom severity, suggesting that duodenal ulcer may be a later manifestation of a milder ulcer-type dyspeptic phase.

(2) Clinical Differences (Table III).-Daily attacks of pain were common in patients with reflux oesophagitis and gastric ulcer, but rare in patients with duodenal ulcer and ulcer-type dyspepsia. Heartburn was present in a very high proportion of patients with reflux oesophagitis (men $100 \%$, women $60 \%$ ), but unfortunately was non-specific, and was also reported frequently in the controls (men $26 \%$, women $18 \%$ ). Stooping tended to aggravate dyspepsia, but relief or aggravation by posture did not differentiate the patients with reflux oesophagitis as we had hoped. A detailed computer analysis failed to reveal any symptom clusters that would enable a clinical distinction to be made between the patients with ulcer-type dyspepsia and duodenal ulcer. The patients with nervous dyspepsia represented a less well defined part of the dyspeptic spectrum and showed a number of statistically significant differences from the other group (Tables III and IV).

(3) Mean Serum Pepsinogen Levels (Table IV).-The mean levels for duodenal ulcer and ulcer-type dyspepsia were raised by statistically significant amounts over the control levels in both men and women. Unfortunately the scatter of results

\begin{tabular}{|c|c|c|c|c|c|c|c|c|}
\hline & \multicolumn{2}{|c|}{$\begin{array}{l}\text { Duodenal } \\
\text { Ulcer }\end{array}$} & \multicolumn{2}{|c|}{$\begin{array}{l}\text { Ulcer-type } \\
\text { Dyspepsia }\end{array}$} & \multicolumn{2}{|c|}{$\begin{array}{l}\text { Nervous } \\
\text { Dyspepsia }\end{array}$} & \multicolumn{2}{|c|}{ Controls } \\
\hline & M. & F. & M. & F. & M. & F. & M. & F. \\
\hline No. cases analysed .. & 109 & 27 & 38 & 29 & 23 & 28 & 112 & 74 \\
\hline $\begin{array}{l}\text { Mean serum pepsi- } \\
\text { nogen (in } \\
\text { units, } \\
\text { Hanley, 1964) } \\
\text { Percentage with blood } \\
\text { group O } \\
\text { Percentage ABH anti- } \\
\text { gen } \\
\text { (saliva) non-secretor } \\
\text { (saliva } \\
\text { no }\end{array}$ & $\begin{array}{l}131^{*} \\
55.9 \\
43.1\end{array}$ & $\begin{array}{l}129 * \\
59 \cdot 3 \\
40 \cdot 8\end{array}$ & $\begin{array}{l}118^{*} \\
47 \cdot 4 \\
26 \cdot 3\end{array}$ & $\begin{array}{l}113^{*} \\
62 \cdot 1 \\
27 \cdot 6\end{array}$ & $\begin{array}{l}103 \\
39 \cdot 1 \\
26 \cdot 1\end{array}$ & $\begin{array}{c}94 \\
42 \cdot 8 \\
17 \cdot 9\end{array}$ & $\begin{array}{c}90 \\
43 \cdot 8 \\
27 \cdot 7\end{array}$ & $\begin{array}{c}80 \\
51 \cdot 3 \\
16 \cdot 1\end{array}$ \\
\hline
\end{tabular}

Only groups containing 20 or more patients have been analysed.

-These mean levels are all significantly higher than the control values at the $1 \%$ level. (The mean levels for duodenal ulcer are higher than the corresponding means for the ulcer-type dyspepsia residue; but these differences are not significantly

was so wide that the serum pepsinogen level was of little diagnostic value in individual cases. The mean serum pepsinogen level was also raised in patients with reflux oesophagitis.

(4) Serological Studies (Table IV).-The percentage of male and fermale patients with blood group $\mathrm{O}$ was higher than the controls in both duodenal ulcer and ulcer-type dyspepsia. Our series was not large enough to show statistically significant differences, but the trend was in keeping with previous work (Aird et al., 1954).

(5) $A B H$ Secretor Status (Table IV).-The percentage of male and female patients with duodenal ulcer who did not secrete $A B H$ antigens in their saliva was higher than the controls and also higher than in patients with both nervous dyspepsia and ulcer-type dyspepsia. These differences were not statistically significant, but the trend was in keeping with previous work (Clarke et al., 1956).

\section{Discussion}

This survey shows the wide and often confusing spectrume of recurrent and chronic dyspepsia as seen by the general practitioner. Detailed investigation and analysis of 1440 patients with a history suggesting duodenal ulcer have showno that hidden beneath the surface are two large groups: (1)을 Patients with pathological diseases that can be identified by radiological investigation-mainly duodenal ulcer. (2) Patients in whom no abnormality can be demonstrated by radiologythat is, ulcer-type dyspepsia. Discussion centres in three related questions : aetiology, diagnosis and prevalence, and? management.

\section{Aetiology of Ulcer-type Dyspepsia}

The main difficulty in estimating aetiology (and prevalence)ivi is that a barium meal may fail to outline an existing ulcer. Eusterman (1936) and Hussar (1948) estimated that 5 to $10 \%, \overrightarrow{0}$ of ulcers are missed, while Littman and Bernstein (1962) put the figure as high as $33 \%$. Barfred (1958) found that out of 147 cases of "pseudo-ulcer" $74(50 \%)$ converted to duodenal? ulcer radiologically within 12 years. Similarly, Lipetz et al.ज (1955) found that only $70 \%$ of his confirmed duodenal ulcer $\triangleright$ cases were diagnosed by radiology at the first examination Of the patients with so-called "non-ulcer dyspepsia" 2.5 tos $13 \%$ eventually proved to have a peptic ulcer (Wilbur and $\overrightarrow{0}$ Mills, 1938; Lipetz et al., 1955; Brummer and Häkkinen, 1959; Krag, 1965).

Judd (1921) described 64 gastroduodenal resections in patients with symptoms simulating duodenal ulcer whos showed grossly inflamed duodenal mucosa without evidenceō of recent or old ulceration. Beck et al. (1965), using maximumő histamine stimulation tests and duodenal biopsies, concluded $\stackrel{\mathbb{Q}}{\mathscr{Q}}$ that "chronic duodenitis" and duodenal ulcer were distinct $\overrightarrow{0}$ clinicopathological conditions. Ostrow and Resnick (1959), 3 using specialized radiological techniques, suggested that duodenitis was an early stage of duodenal ulcer. Edwards and? Coghill (1968) investigated 221 cases of non-ulcer dyspepsia with gastric biopsy and found that a quarter had histological evidence of chronic gastritis. Unfortunately they did not:examine the mucosa of the duodenum.

(1) A duodenal ulcer is present which radiology has failed to reveal. In our survey a barium meal was apparently nor- 0 mal in $40 \%$ of men and $59 \%$ of women with ulcer-type dyspepsia symptoms. Failure of radiological technique is unlikely $\mathcal{N}^{\prime}$ to be responsible for so many cases. Moreover, the failure $?$ rate should be the same in males as in females. The work of Judd (1921) showed that in many of these patients inflamma- $N$ tion was observed at operation, but there was no evidence of $N_{\mathrm{W}}$ present or past ulceration.

(2) Ulcer-type dyspepsia is distinct aetiologically from duodenal ulcer. The similarities of symptoms, age distribu- $\frac{\tau}{\Phi}$ tion, serology, etc., in the two groups of patients make this $\stackrel{\mathbb{P}}{-}$ explanation unlikely.

(3) Ulcer-type dyspepsia represents a pre-ulcer inflammation or duodenitis that is responsible for the symptoms but $\stackrel{\vec{\rho}}{\vec{Q}}$ has not yet progressed to frank ulceration. Such a tentative $\mathbb{Q}$ hypothesis is supported by much of our evidence: $(a)$ The similarity of symptomatology and age of onset. (b) Similarities of serum pepsinogen and blood group distribution. (c) 0 The $24 \%$ of patients with normal barium meals who later developed radiologically demonstrable duodenal ulcers. The reverse-that is, a previously abnormal barium meal later? becoming normal-did not occur. The work of Barfred (1958), Lipetz et al. (1955), and Judd (1921) is in keeping with such an idea. 
Beck et al. (1965) found that in cases of ulcer-type dyspepsia the mucosa showed exactly the same inflammatory changes as the cases of duodenal ulcer. They called this inflammation chronic duodenitis. The symptoms of duodenal ulcer are so similar to those of ulcer-type dyspepsia that we believe they are not due to the ulcer itself but to the state of chronic duodenitis. Nevertheless, the deviation of blood group distribution and of mean serum pepsinogen level from that of controls is less extreme in the ulcer-type dyspepsia cases than in those with frank ulceration. The $\mathbf{A B H}$ antigen secretion in patients with ulcer-type dyspepsia is almost identical to that of controls.

Tentatively we suggest that a precarious equilibrium in the inflamed duodenum occurs between defensive factors such as mucus, female sex hormones, $\mathrm{ABH}$ antigen secretion, etc., and aggresive factors such as gastric acid and pepsin secretion as indicated by raised serum pepsinogen levels. Variations of this equilibrium will lead to ulceration in some cases while in others it stops short of ulceration. In our view our findings support the latter hypothesis: this encourages a more rational approach to the problems facing the general practitioner.

\section{Diagnosis and Prevalence}

The ulcer-type dyspepsia triad of symptoms (pain, periodicity, and relief by alkalis or food) provides a simple and practical screening test for duodenal ulcer or potential ulcer-that is chronic duodenitis. Further radiological investigation of all patients reporting this triad is impracticable on a large scale. Our experience suggests that a general practitioner can in nine months expect a prevalence of about 7.3 cases per 1,000 National Health Service patients. Of these most ( $88 \%$ men, $75 \%$ women) may be taken to have either a duodenal ulcer or a potential ulcer.

Reflux oesophagitis and hiatus hernia, especially in women, may occasionally produce this symptom triad. The presence of daily as opposed to periodic pain strongly suggests a reflux oesophagitis or gastric ulcer rather than a duodenitis or duodenal ulcer. The raised mean serum pepsinogen level noted in oesophagitis may indicate an associated hyperacidity and duodenitis. Upper abdominal pain occurring more than one hour after meals or having a periodicity with six or more attacks in two years suggests that a radiologically demonstrable ulcer may have developed.

\section{Management}

We handle this problem in the early ulcer-type dyspepsia phase by concentrating on medical treatment and getting the patient to live with his symptoms. $\mathrm{He}$ is told that he may have an early ulcer but that $x$-ray examination will not affect the management of the condition and is indicated only when an operation is under consideration. If this is not explained to the patient he may find that his symptoms are similar to those of a friend with a radiologically proved ulcer and demand a barium-meal examination. He is referred for barium meal or second opinion if symptoms are severe enough to interfere with work regularly or if he has more than six attacks in two years. Steadily progressive or daily symptoms may suggest malignancy or hiatus hernia and are handled accordingly. If severe symptoms persist and radiology still fails to show an ulcer some surgeons occasionally consider operative intervention justified. By using these criteria radiological investigation can be reduced or delayed, especially in women under 40.

The concept that a duodenitis precedes the formation of an ulcer and is responsible for many symptoms previously attributed to ulceration encourages a more rational approach to the handling of recurrent dyspepsia in general practice.

We are greatly indebted to Professor Angus Thomson and Mr. W. Z. Billewicz for their help and advice; to Dr. A. K. Lamballe and Dr. C. F. Warrick for performing many extra barium meals; to Mr. Cheyne of the M.R.C. Laboratory, Newcastle upon Tyne, for carrying out the serum pepsinogen estimations; to the medical department, Liverpool University, for carrying out tests on secretor status; and to the M.R.C. for a grant towards this research.

REFERENCES

Aird, I., Bentall, H. H., Mehigan, J. A., and Roberts, J. A. F. (1954). British Medical fournal, 2, 315.

Barfred, A. (1958). In Proceedings of the World Congress of Gastroenterology, vol. 1, p. 352 . Baltimore, Williams and Wilkins.

Beck, I. T., et al. (1965). Gut, 6, 376 .

Beck, I. T., et al. (1965). Gut, 6, 376.

Brummer, P., and Hâkkkinen, I. (1959). Acta Medica Scandina

Doll, R., and Jones, F. A. (1951). Medical Research Council. Special Report Series, No. 276.

Edwards, F. C., and Coghill, N. F. (1968). Quarterly fournal of Medicine, 37, 337 .

Eusterman, G. B. (1936). Fournal of the American Medical Association, 107, 1432 .

Hanley, W. B. (1964). British Medical fournal, 1, 936.

Hussar, A. E. (1948). Gastroenterology, 11, 183.

Judd, E. S. (1921). Lancet, 41, 215.

Krag, E. (1965). Acta Medica Scandinavica, 178, 713.

Lipetz, S., Sklaroff, S. A., and Stein, L. (1955). British Medical fournal, 2, 172 .

Littman, A., and Bernstein, L. M. (1962). Medical Clinics of North America, 46, 747 .

Mirsky, I. A., Flutterman, P., and Kaplan, S. (1952). Fournal of Laboratory and Clinical Medicine, 40, 188.

Ostrow, J. D., and Resnick, R. H. (1959). Annals of Internal Medicine, 51, 1303 .

Spiro, H. M., Ryan, A. E., and Jones, C. M. (1956). Gastroenterology, 30, 563.

Wilbur, D. L., and Mills, J. H. (1938). Annals of Internal Medicine, 12, 821. 